\title{
Occupational Stress, Physical Wellness and Productivity Barometer at Workplace
}

\author{
Jyotirmayee Choudhury
}

Dept of Business Administration Utkal University Vanivihar, Bhubaneswar, Odisha, India.

\begin{abstract}
The paper is a conceptual one to understand the relationship between occupational stress, physical wellbeing and productivity barometer such as burnout, illness, labour turnover and absenteeism. The accumulated unpleasant emotional and psychological feelings ascend out of occupational stress impacts the physical and mental wellness of an employee which ultimately depreciates his/ her productivity barometer. The present paper is a conceptual frame work to understand the concept stress, occupational stress and individual's appraisal of it in his/her work environment. The research work analyses occupational stress as more of a sort of individual generated which rises out of individual's assessment of the stressors of work life. The objective of the research work is to study on occupational stress, physical and psychological wellbeing and productivity barometer. The research article attempts to suggest in promoting health philosophy and physical wellness programme in organisation's work culture and environment through individual initiated interventions and organisation policy to put a control on occupational stress in order to check the alarming signal of productivity barometer.
\end{abstract}

Keywords: Occupational Stress, Physical Wellbeing, Productivity Barometer, Quality of Work Life and Quality of Life.

\section{Introduction}

Stress in general and organizational stress in particular is a universal and frequently disabling human predicament. It has been a part of vocabulary of every man in organisational work space. Stress is state of psychological and physiological imbalance arising out of the disparity between situational demand and the individual's ability and motivation to meet those.

It is becoming obvious part of work life. Stress produces numerous physical and mental conditions which vary according to each individual's perception on threat. Although the degree of experiencing stress is different, it is a common experience to all. Stress experience was first documented by Dr Hans Selye, a pioneer in stress research [1].

According to him, stress causes a variety of psychological conditions including anxiety and depression, mental illness as well as a number of important physical conditions including heart attack, ulcers and stroke. Stress from non-work personal domain such as family and financial problem add to occupational stress. Although it is an individual problem, stress is an integral and inevitable feature of most contemporary workplaces. Work places are becoming a volatile stress factory both for employees and employers. There is a significant correlation between Organizational Climate and Job stress. Occupational and organizational stress is a known factor for health disorder.

Based on an annual survey from the American Psychological Association (APA), 60 percent of people in the United States consider their job a major source of stress. Job stress ranked higher than the economy, family responsibilities and even personal health concerns. Dynamic social factors coupled with changing life style add to it and thereby increasing common stress related reactions such as tension, irritability, inability to concentrate and wide variety of physical symptoms.

Accumulated stress for a longer period of time may break a person both internally and externally and compel him to live in distress and resultant burnout [2]. Prolonged, frequent or intense stress exposure lead towards distress in form of medical, psychological or behavioural unhealthy 
consequences which eventually impact on productivity barometer.

\section{Literature Review}

There is no universal agreement on the definition of stress. McEwen [3] simply states that "Stress is a word used to describe experiences that are challenging emotionally and physiologically". Stress refers to some stimulus resulting in detectable strain that cannot be accommodated by the entity and which ultimately results in impaired health or behaviour.

These stressors may be acute (e.g., hassles) or chronic (e.g., bereavement), small in magnitude (e.g., standing in a long line) or traumatic (e.g., violent attack). Stress may directly affect health behaviours [4]. Stress common among employees may trigger actions from the individuals, groups and the organization. Individual, group and organizational stressors refer to occupational stress. Occupational stress has been expressed by Coopper and Marshall [5] as negative environmental factors or stressors associated with a particular job.

Occupational stress arises due to work situations that place strains on worker's inability to meet work demands which can lead to illness or psychological distress. Occupational stress is a major health problem for both employees and organizations [6]. It can lead to burnout, illness, labour turnover and absenteeism. Occupational stress can also be a barrier to recruiting and retaining workers [7].

Prolonged work stress negatively affects physical and mental health outcomes. Stress proliferation, whereby a stressor or set of stressors can develop beyond a given situation result in additional intention to distort and bring counterattack by the person or object on which it is resisted in psychophysiology.

Occupational stress constitutes any characteristics of job and its environment which poses a threat to the individual. Cooper [8] found that poor physical health is an outcome of occupational stress. Alternatively those who were physically active are less likely to be stressed and better problem solving and coping skills [9]. Work environments are vital to the retention and recruitment of professionals and the sustainability of systems [10]. Researchers have been exploring the subject of occupational stress extensively [11] as it can lead to compromised health and poor performance of employees. The level of occupational stress may vary between different occupations, the position of an individual in the organization, responsibilities and the way one tackle these stressors. But the increasing number of work-stress victims is undoubtedly a matter of concern. Occupational stress has known as one of the factors likely to predict psychological wellbeing. It has become one of the major influences on the health, daily living and psychological well-being of workers [12].

Stress not only contributes to the physical disorders but also to their emotional problems. Stress gives rise to cognitive dysfunction such as dementia [13] and excessive fatigue [14]. Stress may have a direct effect on health such as deregulation of hormonal axes as well as indirect routes toward maladaptation [15] leading towards psychosocial stress and risk of cardiovascular diseases. Stress is related to declining physical function over time [16] and obesity [17].

All these factors coupled together make people vulnerable to different kind of illnesses and involve in unhealthy lifestyles such as excessive consumption of alcohol, smoking, substance abuse and selfmedications, psychological distress, violence and the desire to quit the job. Adegoke [12] reported that there were significant aspects of work-stress, frustration and depression on psychological well-being of employees. He further identified environmental demands especially with regards to time, high workload, low work control, depression and aggression as the aspects of psychological well-being. Akintayo et al [18] reported that there was a significant impact of occupational stress on level of job satisfaction, commitment and compliance of the employees.

Stress affects the employees in an organization probably because shortage of time, heavy workload, conflict of roles, working condition, job and relationships between individuals. It could also be due to individuals' adjustment with respect to their performance and the productivity. Whatever could be the reason, occupational stress can negatively affect employee absence [19], turnover and health problems [8], low 
performance, and individual workers highlighting counterproductive work behaviour. Moreover post-traumatic stress leads towards depression, tension, frustration, sadness and loneliness which ultimately leads towards declining productivity barometer.

\section{Objectives}

- To analyse the concept stress and occupational stress

- To study the co-relation between occupational stress, physical wellbeing and productivity barometer

- To provide suggestions and interventions in controlling and curbing occupational stress

\section{Findings}

Occupational stress is a Global issue in modern life [20-21]. It affects individuals and organisations. Occupational stress is a serious threat to employees' health and their quality of work life. It can cause people to lose their physical, mental and emotional equilibrium to generate hostility, aggression, absenteeism, and turnover and negatively affect productivity [22].

Occupational health risks stems from both physical and mental stress. Occupational stress involves the interaction of work and worker characteristics as well as personal stressors including family responsibilities that influence individuals' appraisal of and coping with workplace situations [23]. Occupational stress has drastic effects on the physical, psychological and behavioral aspects of an individual's life and leads to changes in the personality of the worker. Occupational stress affects each individual's personality in a different way depending on their personality traits.

As a result people may end up with low selfesteem, unhealthy relationships and may exhibit risk-taking behavior such as alcohol consumption and even suicide. This global issue needs to be addressed timely with positive stress-coping techniques. According to Williams and Cooper [24], work stress is one of the main issues in the occupational safety

\section{Conclusion}

Occupational stress is an inevitable as an integral element of the work environment. Stress is not immune to any organisation. But it has captured the attention of researchers as well as practitioners to not to be allowed to health and organizational welfare which ought to be the concern of every organisation.

\section{Suggestions}

The burning issue of occupational stress can only be addressed when organizations play their part in helping the employees to cope with it. All institutions must set up a support cell to deal with the physical and psychological concerns of staff members [25]. Health philosophy has to be ingrained, preached and practised in organisational philosophy because health is contagious in nature.

A recent Social network study done by Nicholas Christakis and James Fowler [26] a physician and professor of medical sociology has concluded his 32 years of study by saying that if somebody's friend is obese, then his risk of getting obese is 45 percent higher. Obesity is spreadable in social sense. Therefore, a fitness philosophy definitely has the potential to be contagious and spread over the workforce who ultimately brings magical personal transformation by creating and maintaining a fitter, stronger and healthier and disciplined individual with lot of confidence and competence and determination.

Ultimately the health thermometer will have its impact on productivity barometer in terms of decrease in absenteeism higher job satisfaction, higher employee retention, lower healthcare cost and lower productivity. Subsequently the organisation will have an agile and vibrant workforce to face constant challenges of market demand which will be the starting point of employee engagement.

As engagement starts with concern and care, it harmonises employee- employer relationship by establishing conducive work environment, promoting health awareness, providing avenues to stay healthy, nurturing psychologically safe workplace and caring beyond work. Then the workplace will not then be a mecca of mere business transactions but become a fulfilling space catering not only good quality of work life but also a good life.

translate into organizational dysfunction in the form of medical, psychological or behavioral distress. It needs to be managed and curbed through different forms of interventions and policies. Occupational stress 
affects the human behaviour in the organization through its impact on employee performance, satisfaction and attitudes. Therefore, promoting and implementing a preventive simple stress management measures such as promoting physical wellbeing in the form of interventions and health policies may avert distress to foster human contentment and satisfaction in raising productivity barometer. It is crucial that management must foster an environment that can appreciate the realities of work environment to bring an overhaul in quality of work environment and quality of work life. It will improve the general health of employees

\section{References}

1. Selye H (1974) Stress without Distress: New York: Lippincott.

2. Greenglass E, Burke R (1999b) Burnout artd restructuring: Implications for Psychological Functioning. Paper presented at the VI European Congress of Psychology, Rome, Italy, 4-9.

3. McEwen BS (2007) Physiology and neurobiology of stress and adaptation: central role of the brain. Physiol Rev, 87(3):873-904.

4. Selena T, Nguyen-Michel, Jennifer B, Unger, Jeff Hamilton, Donna Spruijt-Metz (2006) Associations between physical activity and perceived stress/hassles in college students: Stress and Health, 22: 179-188.

5. Cooper CL, Marshall J (1976) Occupational sources of stress: a review of the literature relating to coronary heart disease and mental ill health. "Journal of occupational psychology, 49 (1):11-28.

6. Edward A, Charlesworth (2004) Stress Management: A Comprehensive Guide to Wellness.

7. Bartram T, Joiner TA, Stanton P (2004) Factors affecting the job stress and job satisfaction of Australian nurses: Implications for recruitment and retention. Contemporary Nurse, 17:293-304.

8. Cooper CL (1983) Identifying Stressors at Work: Recent Research Developments, Journal of Psychosomatic Research, 27: 369-376.

9. Largo-Wight E, Peterson M, Chen WW (2005) Perceived Problem Solving, Stress, and Health Among College Students: which subsequently add to their enhanced performance and the company's progress.

- 0b013e318240a65a

- Bartram, T., Joiner, T. A., \& Stanton, P. (2004). Factors affecting the

- Job stress and job satisfaction of Australian nurses: Implications

- For recruitment and retention. Contemporary Nurse, 17, 293-304.

- Doi:10.5172/conu.17.3.293

- Bourbonnais,

American journal of health behaviour, 29 (4):360-70.

10. Pino O, Rossini G (2012) Perceived organizational stressors and inter-personal relationships as predictors of job satisfaction and well-being among hospital nurses. International Journal of Psychology and Be-havioral Sciences, 2:196-207.

11. Mazzola JJ, Schonfeld IS, Spector PE (2011) what qualitative research has taught us about occupational stress? Stress Health, 27(2):93-110.

12. Adegoke TG (2014) Effects of occupational stress on psychological wellbeing of police Employees in Ibadan Metropolis, Nigeria. An International Multidisciplinary Journal, Ethiopia. 8 (1):302 -320.

13. Sandi C (2004) Stress, cognitive impairment and cell adhesion molecules. Nat Rev Neurosci, 5(12):917-30.

14. Theorell-Haglow J, Lindberg E, Janson C (2006) What are the important risk factors for daytime sleepiness and fatigue in women? Sleep, 29(6):751-7.

15. Hamer M (2012) psychosocial stress and cardiovascular disease risk the role of physical activity. Psychosom. Med, 74(9):896-903.

16. Cheng YW, Kawachi I, Coakley EH, et al (2000) Association between psychosocial work characteristics and health functioning in American women: prospective study. BMJ, 320(7247):1432-6.

17. Ogden LG, Stroebele N, Wyatt HR et al (2012) Cluster analysis of the national weight control registry to identify distinct 
subgroups maintaining successful weight loss. Obesity, 20(10):2039-47.

18. Akintayo I, Babajide EO (2011) Occupational stress, psychological wellbeing and workers behaviour in manufacturing industries in south west Nigeria, Inter J Manage and Innov 3: 3242.

19. Cartwright S, Cooper CL (2002) ASSET: An Organisational Stress Screening Tool, Robertson Cooper Limited and Cubiks, London.

20. Smith A (2000) the scale of perceived occupational stress. Occup. Med., 50: 294298.

21. Chang K, Lu L (2007) Characteristics of organizational culture, stressors and wellbeing: The case of Taiwanese organizations. J. Manag. Psychol., 22: 549 568.

22. Mosadeghrad AM, Ferlie E, Rosenberg D (2011) a study of relationship between job stress, quality of working life and turnover intention among hospital employees. Health service management research, 24(4):170-81.

23. Zeller JM, Levin PF (2013) Mindfulness interventions to reduce stress among nursing personnel: an occupational health perspective. Workplace Health Safety, 61(2):85-9.

24. Williams S, Cooper L (2002) "Managing Workplace Stress", Facilities, 20 (10): 349349.

25. Akintayo DI (2012) Occupational stress, psychological well-being and workers' behavior in manufacturing industries in South-west Nigeria. Organizational Psychology \& Educational Studies, 1(5):289-294.

26. Christakis N, James Fowler J (2007) The Spread of Obesity in a Large Social Network over 32 Years N. Engl. J. Med, 357:370-379. 